\title{
e-Migrinter
}

15 | 2017

Migrinter a trente ans : analyses et portraits

\section{Portrait d'Audrey Brosset, éditrice de la REMI, bureau 016}

\section{Audrey Brosset}

\section{(2) OpenEdition}

\section{Journals}

Édition électronique

URL : https://journals.openedition.org/e-migrinter/840

DOI : 10.4000/e-migrinter.840

ISSN : 1961-9685

Éditeur

UMR 7301 - Migrinter

Référence électronique

Audrey Brosset, "Portrait d'Audrey Brosset, éditrice de la REMI, bureau 016 », e-Migrinter [En ligne], 15 | 2017, mis en ligne le, consulté le 20 mai 2021. URL : http://journals.openedition.org/e-migrinter/840 DOI : https://doi.org/10.4000/e-migrinter.840

Ce document a été généré automatiquement le 20 mai 2021.

Tous droits réservés 


\title{
Portrait d'Audrey Brosset, éditrice de la REMI, bureau 016
}

\author{
Audrey Brosset
}

\section{NOTE DE L'ÉDITEUR}

Ce billet fait partie d'une série de quatre portraits réalisés à partir d'un questionnaire initié par Sarah Przybyl et Julie Lemoux.

Quel est ton poste et depuis combien de temps travailles-tu à la REMI ? Que faisais-tu avant de travailler à la REMI ?

Je suis secrétaire de rédaction de la REMI (Revue Européenne des Migrations Internationales) depuis 7 ans. Avant cela, j'ai travaillé en tant que documentaliste en collège/lycée après avoir obtenu un DEA d'histoire médiévale dont le sujet de recherche était "Les reliques dans les abbayes cisterciennes d'Occident (XIIèmeXIVème s.) ».

\section{Comment défınirais-tu ta mission à la REMI ?}

Ma mission à la REMI consiste à prendre en charge la chaîne éditoriale (contacts avec les auteurs, gestion des évaluations d'articles, collecte des contenus, vérification de la cohérence, de la typographie, de l'orthographe et de la syntaxe, mise aux normes, préparation des contenus, etc.) et à gérer les activités liées à une publication scientifique (comité de rédaction, imprimeur, mise en ligne, budget, etc.).

Pourrais-tu nous décrire en quelques mots une journée-type?

Je n'ai pas vraiment de journée-type. L'organisation de mon temps de travail dépend plutôt de l'état d'avancement des parutions (quatre fois par an) et des urgences ! Mais de manière générale, je passe un bon quart, voire la moitié, de ma journée sur ma boîte mail (le matin surtout) pour gérer la vie de la revue et le reste du temps, je fais de l'édition de textes, de la programmation assistée par ordinateur (PAO), de la mise en ligne, etc. 
Peux-tu nous faire part d'un événement, d'une anecdote ou d'une rencontre qui, au cours de ton expérience à la REMI, ont marqué ta carrière et/ou ta vision des migrations internationales?

La REMI a 30 ans cette année. Pour fêter cet anniversaire, nous avons organisé le dernier comité de rédaction de la revue à Poitiers (habituellement les comités se déroulent à Paris). Ce comité, composé de géographes, démographes, juristes, sociologues, anthropologues, historiens, de membres fondateurs de la revue, de nouveaux venus, d'enseignants, de chercheurs, a été l'occasion d'apprécier l'implication de chacun d'entre eux pour la REMI et, de manière plus générale, pour les migrations internationales. Il a été l'occasion de montrer que la REMI, par sa pluridisciplinarité et la multiplicité des laboratoires de recherche qui la composent, a encore des années de publication devant elle.

As-tu été marqué par un (ou plusieurs) événement en particulier au cours de ta carrière à la REMI ? (évolution de poste, arrivée/départ d'un collègue, changement de direction, etc.)

Ma carrière a été marquée par des rencontres. Ces rencontres, ce sont celles que j'ai faites avec les différent(e)s directeurs/rices de la REMI: Marie-Antoinette Hily, William Berthomière, Véronique Petit, Emmanuel Ma Mung. Occuper la fonction de direction de cette revue scientifique demande du temps et de l'investissement et ça demande aussi de passer beaucoup de temps avec moi! En travaillant avec chacun d'entre eux, j'ai appris à les connaître et, chacun à leur manière, ils m'ont beaucoup appris sur leur façon de penser les migrations internationales et de les écrire...

Pourrais-tu donner trois mots qui définissent Migrinter à tes yeux?

Tolérance, Discernement, Convivialité.

UNE IMAGE..

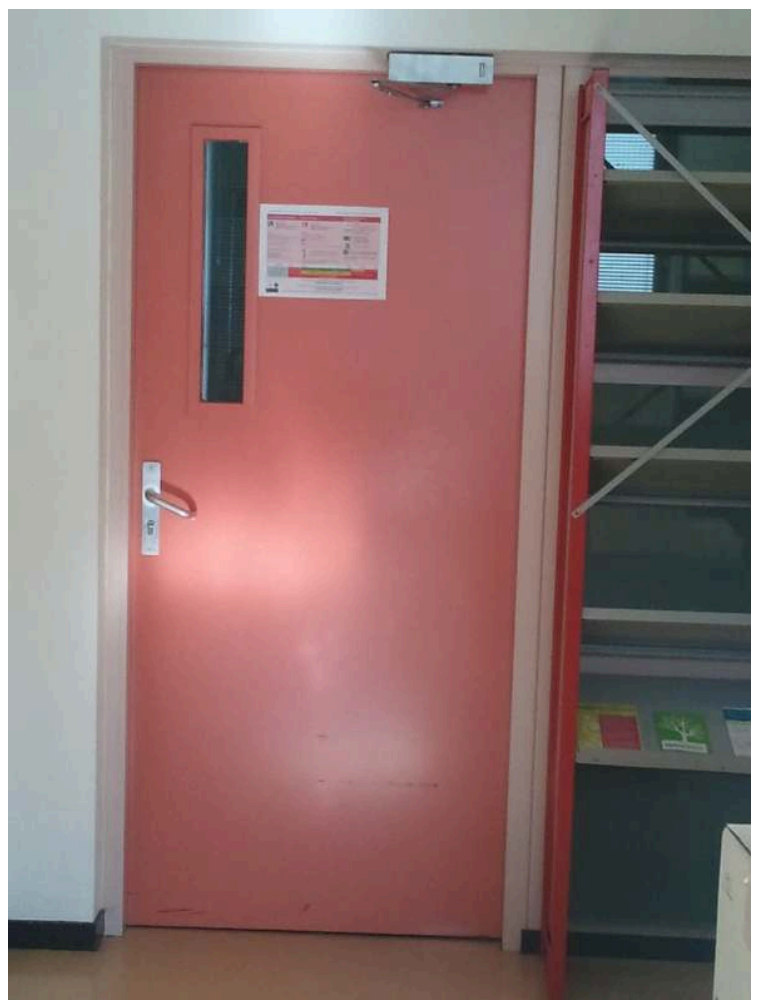


1 Voici ma porte de bureau (du moins la partie visible depuis mon bureau). C'est par cette porte que passent les collègues de Migrinter pour venir dire bonjour, au revoir ou prendre le café... et il y a beaucoup de collègues à Migrinter, donc beaucoup de passages... et c'est bien!

\section{AUTEUR}

\section{AUDREY BROSSET}

Ingénieure d'étude à l'Université de Poitiers, Revue Européenne des Migrations Internationales (REMI) / MSHS

audrey.brosset@univ-poitiers.fr 